University of Wollongong

Research Online

Faculty of Engineering and Information

Faculty of Engineering and Information

Sciences - Papers: Part B

Sciences

2019

Contradictions in information technology mediated work in long-term care: An activity theoretic ethnographic study

Siyu Qian

University of Wollongong, sqian@uow.edu.au

Ping Yu

University of Wollongong, ping@uow.edu.au

Anol Bhattacherjee

University of South Florida, abhatt@usf.edu

Follow this and additional works at: https://ro.uow.edu.au/eispapers1

Part of the Engineering Commons, and the Science and Technology Studies Commons

Research Online is the open access institutional repository for the University of Wollongong. For further information contact the UOW Library: research-pubs@uow.edu.au 


\title{
Contradictions in information technology mediated work in long-term care: An activity theoretic ethnographic study
}

\author{
Abstract \\ Background: The growing demand for aged care services coupled with a global shortage of skilled \\ nursing staff has hindered long-term care facilities' ability to provide necessary services to their residents. \\ Healthcare information technology is expected to mitigate this challenge by streamlining nursing work, \\ while also improving quality of care and productivity. \\ Objectives: This study set out to examine how nurses and care workers work, the role of information \\ technology (IT) in their work and what contradictions they face in their IT mediated work. \\ Design: Ethnographic study informed by six components of activity theory: subject, object, tool, rule, \\ community and division of labor. \\ Setting: Eight care units in two long-term care facilities in Australia. Participants: Eleven staff from two \\ long-term care facilities including registered nurses $(n=2)$, endorsed enrolled nurses $(n=5)$ and personal \\ care workers $(n=4)$ participated in this study. \\ Methods: Participants were shadowed during morning shifts (6:30 am to 3:00 pm). A total of 24 morning \\ shifts were observed over four months. Field notes were created based on observational data and \\ informal interviews, in addition to document review. \\ Results: Through the lens of activity theory, the work activity system of nurses and care workers in the \\ long-term care facilities consisted of the subject (nurses and care workers), their object (resident care), \\ tools used for work including IT, rules of work, community, and division of labor. These components \\ interacted through work processes; therefore, a "process" component was added in the activity system. \\ Special attention was given to the role of IT as the conduit of information in the work processes. Although \\ IT helped track medication rounds, automated documentation and communication among the staff, it \\ introduced contradictions. Seven contradictions involving IT were identified, including contradictions \\ within the IT tool, between the IT tool and the object of work, between the subjects and documentation \\ rules, between the work activity system using paper records and the system using IT, and between the \\ activity system within the long-term care facility and the pharmacists' work activity system outside the \\ facility.
}

Conclusions: Activity theory provided a theoretic framework to model the work activity system of nurses and care workers. Information technology played an important role in supporting information flow in this system, however it also caused contradictions.

Disciplines

Engineering | Science and Technology Studies

\section{Publication Details}

Qian, S., Yu, P. \& Bhattacherjee, A. (2019). Contradictions in information technology mediated work in long-term care: An activity theoretic ethnographic study. International Journal of Nursing Studies, 98 9-18. 


\section{International Journal of Nursing Studies}

2

3 Article title: Contradictions in information technology mediated work in long-term care:

4 An activity theoretic ethnographic study

5

\section{Authors}

$7 \quad$ Siyu Qian ${ }^{1}$, Ping $\mathrm{Yu}^{1}$, Anol Bhattacherjee ${ }^{2}$

$8{ }^{1}$ Centre for IT-enabled Transformation, School of Computing and Information Technology,

9 Faculty of Engineering and Information Sciences, University of Wollongong, Wollongong,

10 New South Wales 2522 Australia

$11{ }^{2}$ Muma College of Business, University of South Florida, Tampa, Florida 33620 USA

12

13 Corresponding author

14 Siyu Qian, PhD

15 Research associate

16 Centre for IT-enabled Transformation

17 School of Computing and Information Technology

18 Faculty of Engineering and Information Sciences

19 University of Wollongong

201sq992@uowmail.edu.au

21 phone: +61 0242213074

22

fax:+61 0242214045 


\section{Abstract}

2 Background The growing demand for aged care services coupled with a global shortage of skilled nursing staff has hindered long-term care facilities' ability to provide necessary services to their residents. Healthcare information technology is expected to mitigate this challenge by streamlining nursing work, while also improving quality of care and productivity.

Objectives This study set out to examine how nurses and care workers work, the role of information technology (IT) in their work and what contradictions they face in their IT mediated work.

Design Ethnographic study informed by six components of activity theory: subject, object, tool, rule, community and division of labor.

Setting Eight care units in two long-term care facilities in Australia.

Participants Eleven staff from two long-term care facilities participated in this study.

Methods Participants were shadowed during morning shifts (6:30 am to 3:00 pm). A total of 24 morning shifts were observed over four months. Field notes were created based on observational data and informal interviews, in addition to document review.

Results Through the lens of activity theory, the work activity system of nurses and care workers in the long-term care facilities consisted of the subject (nurses and care workers), their object (resident care), tools used for work including IT, rules of work, community, and division of labor. These components interacted through work processes; therefore, a "process" component was added in the activity system. Special attention was given to the role of IT as the conduit of information in the work processes. Although IT helped track medication rounds, automated documentation and communication among the staff, it introduced contradictions. Seven contradictions involving IT were identified, including contradictions within the IT tool, between the IT tool and the object of work, between the subjects and documentation rules, between the work activity system using paper records and the system using IT, and between the activity system within the long-term care facility and the pharmacists’ work activity system outside the facility.

Conclusions Activity theory provided a theoretic framework to model the work activity system of nurses and care workers. Information technology played an important role in supporting information flow in this system, however it also caused contradictions. 
1 Keywords: Activity theory; contradiction; electronic medication administration record; 2 ethnographic research; information technology; IT use; long-term care; nurse; observation; 3 residential aged care

4 


\section{Introduction}

Ageing populations are causing an unprecedented growth in the demand for aged care services in many countries. In the next three decades, the aged population is projected to reach 19.7 million (25\% of the population) in the UK (Office for National Statistics, 2014), 83.7 million (21\%) in the US (Ortman et al., 2014) and 8.8 million (22\%) in Australia (Australian Institute of Health and Welfare, 2018).

Long-term care facilities (LTCFs) provide aged care services to older people for whom other living arrangements are no longer sustainable or meeting the needs of the older person. These services include accommodation, laundry, meals, nursing care such as medication administration, wound care, and catheter care, and personal care such as showering, dressing, and toileting (Qian et al., 2016, Qian et al., 2012). However, a global shortage of skilled staff is hindering LTCFs' ability to provide these necessary services. It has been suggested that healthcare information technology (IT), such as electronic health record (EHR) system and electronic medication administration record (eMAR) system, may partially mitigate this staff shortage by streamlining work processes (Cherry et al., 2008, Zhang et al., 2012), while improving quality of care (Fichman et al., 2011, Kelley et al., 2011) and care productivity (Fichman et al., 2011, Hersh, 2009).

Information technology use in the work of nurses and care workers has many benefits, including improved information accuracy, legibility, completeness, speed of data entry and retrieval, internal and external communication, their understanding of residents' needs and their ability to determine a resident's risk level (Florczak et al., 2012, Munyisia et al., 2011, Zhang et al., 2012). But IT also has unintended adverse consequences such as increased complexity of information management and documentation, reduced face-to-face communication, increased difficulties in care coordination, and workarounds to medication safety features in the system (Vogelsmeier et al., 2008, Yu et al., 2013). Due to these negative consequences, many staff view IT as a disruption to their work. In order to leverage the potential of IT in the work of nurses and care workers, there is a need to understand how IT may or may not fit into their daily work.

This study is part of a PhD work which investigates nurses and care workers' work in Australian LTCFs. The IT-related workflow and its impacts have been reported (Qian and Yu, 2014, Qian et al., 2015). The research questions of interest to this study include: (1) how do nurses and care workers work? (2) what is the role of IT in their work? (3) what contradictions do they face in their IT-mediated work? These questions were explored using an ethnographic study of two Australian LTCFs through the lens of activity theory. 


\subsection{Nurses and care workers in Australian long-term care facilities}

In Australia, the LTCF nurses and care workers include registered nurses (RNs, 14.9\%), enrolled nurses (ENs) or endorsed enrolled nurses (EENs) (11.5\%) and personal care workers (PCWs, 68.2\%) (Munyisia et al., 2011, Qian et al., 2018, Willis et al., 2016). An RN requires a bachelor degree in nursing and registration with the Nursing and Midwifery Board of Australia. An EN requires a diploma in nursing from an accredited agency and also successful registration with the Nursing and Midwifery Board of Australia (National Enrolled Nurse Association of Australia). A PCW, also known as assistant in nursing, requires Certificate III or Certificate IV in Aged Care from an accredited agency and four weeks to six months of full-time training (Senate Community Affairs Committee, 2017).

The RNs act as the team leaders or unit managers. They are responsible for complex or specialized nursing activities such as health assessment and administration of addictive medicine (Qian et al., 2016). The ENs provide basic nursing care such as observing, measuring and recording residents' temperature, pulse, respiration and blood pressure, in addition to personal care. The endorsed ENs (EENs) have further medication endorsement and thus can provide comprehensive medication management (McEwan, 2008). The PCWs provide personal care (e.g. showering), but may also be trained to provide some clinical care under the supervision of RNs (Qian et al., 2016).

\subsection{Theoretical framework}

Activity theory is "a philosophical and cross-disciplinary framework for studying different forms of human practices as development processes, at both individual and social levels interlinked at the same time” (Kuutti, 1996, p. 7). This framework can be used to analyze the different components of human activities, such as participants in the activity, tools used, rules followed, and so forth, within their socio-cultural contexts. Originally developed by Russian psychologists Lev Vygotsky and Alexei Leontiev, this theory subsequently became the basis of a new tradition of cultural-historical psychology based on the idea that human consciousness and actions are shaped by their socio-cultural context, as an alternative to western psychology that viewed human minds and societies as distinct and separable entities.

Activity theory views an activity system as a collective social action consisting of six components: object (the desired goal of the activity), subjects (people performing the activity), tools (artifacts used to conduct that activity), community (the social collective within which the activity is performed), rules (that govern subjects' behaviors in activity 
1 performance) and division of labor (or roles i.e. the specific responsibilities assigned to each 2 subject by the community) (Engeström, 1987).

Tools mediate subjects' performance of an activity toward a desired goal (object). Wartofsky classified mediating tools as primary, secondary and tertiary (Wartofsky, 2012). Primary tools are material or physical artefacts used in activity performance, such as IT. Secondary tools are psychological tools, such as language, signs, ideas and mental models that help subjects understand, communicate and document their activities. Tertiary tools are socio-cultural tools, such as cultural systems, environment, context and virtual space that may influence subjects' performance. Tools carry historical knowledge of how people work or how work activities are organized (Kuutti, 1996). While tools mediate human activities, activities may also lead to the modification of tools, such as personalization of an EHR system to fit work process better.

In prior research, activity theory has been used to analyze individual and collective work by organizational employees and managers (Kuutti, 1996, Nardi, 1995). This theory has also been used to examine how IT implementations disrupt, change, or improve organizational work activities and their emergent consequences. For example, Allen et al. (2013) conducted an empirical study to examine the contradictions engendered by a mobile health system and an incident control system in the UK Ambulance and Patient Transport Service. Woll and Bratteteig (2018) analyzed technology mediated homecare for older people living in private homes through the lens of activity theory. In LTCF contexts, however, the application of activity theory has been sparse.

\subsubsection{Contradictions in activity theory}

Contradiction is a relatively recent concept in activity theory. Contradictions can be defined as "denials, conflicts or inconsistencies that manifest themselves within and between components of an activity system that interfere the flow of work” (Ngoma and Igira, 2012, p. 511). They reduce motivation for improvement efforts, changes, developments and innovations in people’s work (Engeström, 2000, Engeström and Sannino, 2011). For example, contradictions between tools and work may reduce subjects' motivation to employ those tools in their work activities, and perhaps create resistance toward tools. 


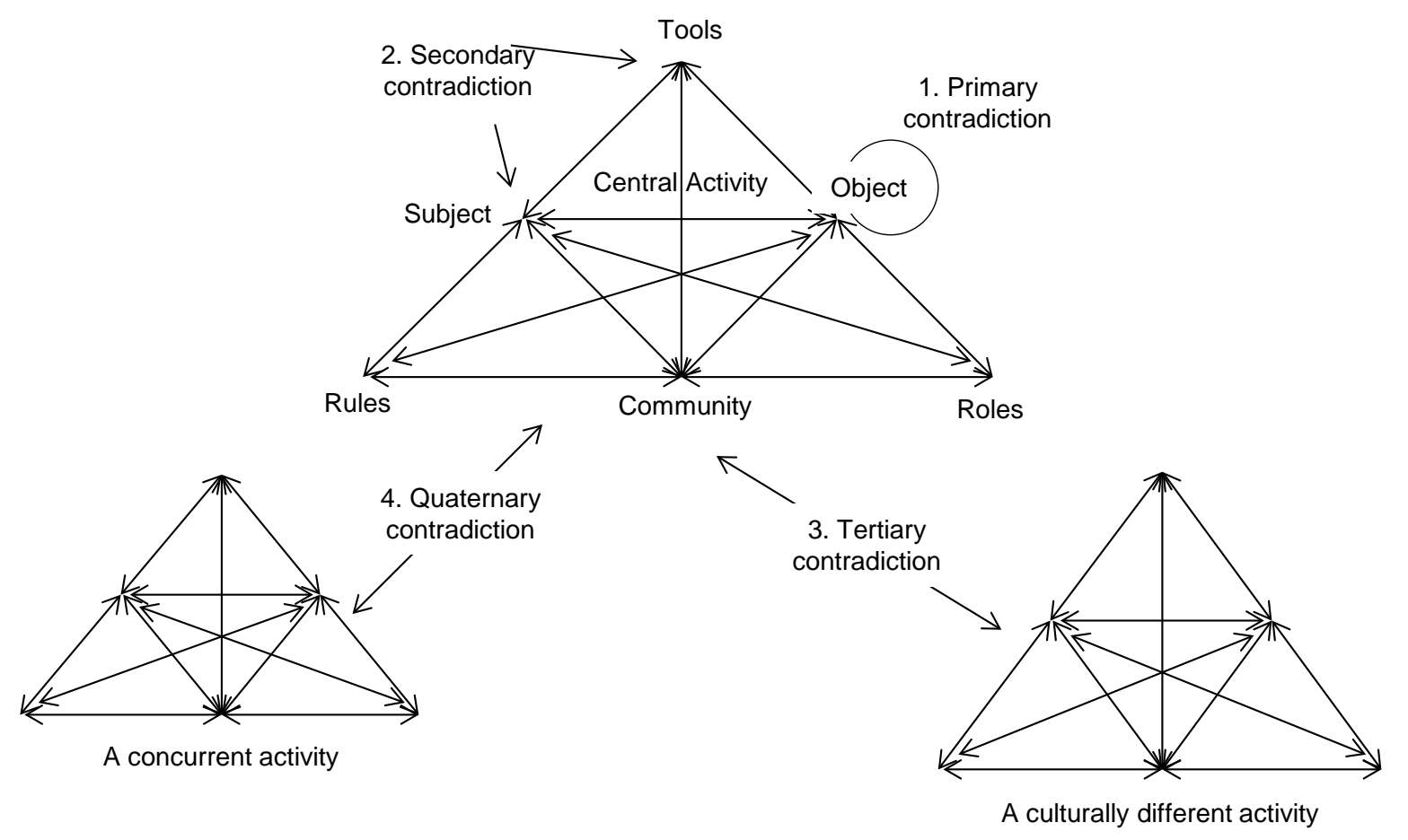

Figure 1. Four levels of contradictions in activity theory (Engeström, 1987).

Engeström (2000) described four levels of contradictions in activity theory (Figure 1). Primary contradictions occur within one of the six components of an activity system. For example, frequent computer system crashes may be a primary contradiction within the tool component. Secondary contradictions occur between two components of an activity system. For example, Ngoma and Igira (2012) described an instance where community health workers in Tanzania were entrusted with the object of recording maternal health data but were not given tools to do so.

Tertiary contradictions occur when a component of an activity system conflicts with that of a culturally different activity system often introduced to replace the initial system. For example, Karanasios and Allen (2014) investigated a situation where police officers, who traditionally documented case encounters on paper notepads, were asked to do the same using mobile technologies. This mobile technology was a culturally more advanced tool than paper records because it had built-in capability to check person and vehicle, record crime reports, view prior data involving the same person, and so forth. In this example, tertiary contradictions manifested in the form of workarounds to the new system in order to reduce its disruptive effect on the historically established police work behaviors.

Quaternary contradictions appear between the central activity system and a neighboring or interacting activity system. For example, in a study of IT innovation and organizational transformation, a quaternary contradiction was identified when the object of collected data in 
the health information management activity system could not facilitate the object of decision making in the health management activity system (Igira and Aanestad, 2009). These contradictions provide a conceptual framework to guide the identification of contradictions in IT-mediated work at LTCFs.

\section{Research methods}

\subsection{Ethnographic study}

Field data collection was conducted for four months between June and September 2013. Seminal ethnographic work (ØSterlund, 2007, Taxis and Barber, 2003) guided our data collection and analysis. Table 1 presents information about our study sites: eight care units located in two aging-in-place LTCFs. During data collection, the bed occupancy rate at these LTCFs was above $90 \%$.

Table 1. Ethnographic study sites and the participants.

\begin{tabular}{|c|c|c|c|c|}
\hline $\begin{array}{l}\text { Care } \\
\text { unit }\end{array}$ & Facility & $\begin{array}{l}\text { No. of } \\
\text { beds }\end{array}$ & Staff mix in a morning shift & Participants \\
\hline 1 & 1 & 38 & $\begin{array}{l}1 \text { EEN or } 1 \text { RN } \\
6 \text { PCWs with Certificate III in Aged Care }\end{array}$ & \multirow{2}{*}{$\begin{array}{l}1 \text { RN } \\
4 \text { EENs } \\
2 \text { PCWs with Certificate IV } \\
\text { level II in medication } \\
\text { management }\end{array}$} \\
\hline 2 & 1 & 40 & $\begin{array}{l}1 \text { EEN or } 1 \text { RN } \\
6 \text { PCWs with Certificate III in Aged Care }\end{array}$ & \\
\hline 3 & 1 & 40 & $\begin{array}{l}1 \text { PCW with Certificate IV level II in } \\
\text { medication management } \\
2 \text { PCWs with Certificate III in Aged Care } \\
1 \text { Floater (helping hand) }\end{array}$ & \multirow[t]{3}{*}{$\begin{array}{l}2 \text { PCWs with Certificate IV } \\
\text { level II in medication } \\
\text { management }\end{array}$} \\
\hline 4 & 1 & 16 & \multirow{2}{*}{$\begin{array}{l}1 \text { PCW with Certificate IV level II in } \\
\text { medication management } \\
2 \text { PCWs with Certificate III in Aged Care }\end{array}$} & \\
\hline 5 & 1 & 11 & & \\
\hline 6 & 2 & 25 & \multirow{3}{*}{$\begin{array}{l}1 \text { RN } \\
1 \text { EEN } \\
8 \text { PCWs with Certificate III in Aged Care }\end{array}$} & \multirow{3}{*}{$\begin{array}{l}1 \mathrm{RN} \\
1 \mathrm{EEN}\end{array}$} \\
\hline 7 & 2 & 22 & & \\
\hline 8 & 2 & 14 & & \\
\hline
\end{tabular}

RN: registered nurse; EEN: endorsed enrolled nurse; PCW: personal care worker

Our study focused on nursing care, mainly medication and wound care, since, unlike personal care, nursing care required frequent interaction with IT systems. Some PCWs were trained to provide medication and wound care at our study sites. They were PCWs with Certificate IV and were recruited in our study. However, PCWs with Certificate III provided personal care only, thus were excluded from our study. In total, eleven participants, including the two RNs, five EENs and four PCWs with Certificate IV level II in medication management, consented to participate in the study. Their average years of work experience in the current role were 6.7 years. Only one participant was male.

The primary method of data collection was observation. The observer (first author) was a $\mathrm{PhD}$ candidate at the time of this study and was trained by an experienced researcher in the 
1 topic area to observe nurses and care workers' work in Facility 1 for 14 days. The observer

2 had three years of research experience in LTCFs prior to the commencement of the ethnographic field observations. To minimize "Hawthorne effect" (Finkler et al., 1993), the observer established rapport and trust with them through repeated interactions, so that she would not be seen as an "outsider" (Ampt et al., 2007). Furthermore, nurses and care workers at this LTCF were comfortable with being shadowed and observed by nursing students in nursing training, and viewed the observer as a research student undergoing similar training.

The observer spent 24 morning shifts (6:30 am to 3:00 pm), totaling 204 hours over four months, in shadowing the participants. She was culturally immersed in the data collection process, and documented rich information about nurses and care workers' work activities, processes, and contradictions in their activities. Some unexpected work activities were observed, such as when some nurses and care workers did not enter resident medication information on the computer right after administration as procedurally required, but made personal notes on paper for each resident and entered all data into the computer in batch mode at a later time.

Informal interviews are routinely used by ethnographers to discuss and probe emerging issues or unusual events in a naturalistic manner (Reeves et al., 2008). Using this method, the first author asked questions to the nurses and care workers between their work and during breaks about their work activities, procedures, and IT use. Participants' responses were recorded in field notes. Examples of questions asked include:

- What information or functions provided by the electronic records are useful for your work? Why?

- What barriers or inconvenience have you encountered when using the electronic records? How do you overcome these barriers or inconvenience?

- Compared to the traditional paper records, what are the advantages and disadvantages of the electronic records? Why?

Ethnographic field notes included observational notes, informal interview questions and answers, relevant conversations related to the work of nurses and care workers, and notes about the contextual factors. In addition, nursing policies, guidelines, incident reports and user manual of the electronic records were also reviewed to understand the work context and to situate the observations and interpretation within this socio-cultural context.

After 24 shifts of observations and analysis during the four-month time period, no new variations in work patterns or further behaviors emerged, thus our analysis was "theoretically saturated” and observations were stopped. 


\section{$1 \quad 2.2$ Ethics approval and consideration}

2 The study was approved by the Ethics Committee of the university and the partner LTCFs.

3 Prior to the commencement of the study, information sheets were provided to the LTCFs to inform the staff, residents and relatives about the research. Informed consent was obtained from all participants before the observation started. Participants were assured that no confidential or identifiable information was being recorded. Though the focus of the study was to understand their work, it was unavoidable that the observer would indirectly observe the residents and their interactions with nurses and care workers during care provision such as medication delivery or wound care. However, to protect resident privacy, no identifiable information was recorded about the residents.

\subsection{Data analysis}

Ethnographic field notes and the collected documents were reviewed and analyzed at the end of each day. Data classification and organization were focused around the three research questions: how nurses and care workers worked (i.e. their work activity system), role of IT, and contradictions from IT use. It was informed by the six components of activity theory: subject, object, tool, rule, community and division of labor. Keywords that could be mapped to one of these six components were highlighted. As coding proceeded, additional codes such as "work process" were identified, with two sub-codes: medication administration process and wound care process.

The notes were read several times to identify and highlight content related to IT use. Concepts emerged from these content included when (e.g. medication preparation), where (i.e. at the point-of-care or in the office) and the purpose (e.g. documentation) of IT use by nurses and care workers. Some concepts such as "interaction points of IT with the work processes" were grouped into higher-order concepts such as "role of IT" to align with our activity theoretic analysis. Four specific roles of IT also emerged from the notes related to IT use: tracking of progress of medication administration, automation of the documentation process, automation of the communication process, and information entry, storage and retrieval.

Since IT tools are considered to be a culturally more advanced substitute to paper records, the same analysis procedure was followed to identify the role played by the paper records, for comparing with IT tools, a new concept called “role of paper records” was created.

Disturbances (e.g., breakdowns) in the work processes were seen as manifestations of contradictions within or between activity systems. Disturbances were classified into four subcodes: primary, secondary, tertiary and quaternary. Coding results were reviewed by the second author to corroborate the analysis. 
3

\subsection{Study rigor}

Following Krefting's (1991) suggestion that the credibility of qualitative research can be established through intensive observations and data triangulation, the following efforts were made to ensure study credibility and rigor. First, field observations were conducted by a trained observer and triangulated using interviews and supplementary documents. Second, the first and second authors regularly met to review and discuss the collected data and analysis results. Third, to ensure the auditability of the study, a detailed, clear documentation was maintained, describing the daily schedule, data collection methods, exception handling, decisions and rationale about the decisions made by nurses and care workers, and the observer's own thoughts.

\section{Findings}

\subsection{How do nurses and care workers work?}

Using the activity theory lens (Figure 2), the "subjects" in this activity system were the nurses and care workers, whose "object" was to care for residents (e.g., medication administration, wound care). The “community” included LTCF staff, residents' families and friends, volunteers and external health service providers. The LTCFs staff included care team, facility administrators and logistic support group. External health service providers included general practitioners, dentists, optometrists, and aged care regulatory body. The "rules” included organizational policies, roles and care practice guidelines, such as appropriate ways of measuring and administering medications, sanitizing and dressing a wound, and documenting the care. Different community members took on different "roles" such as RN, EEN and PCW in care provision.

Common "tools" used by the nurses and care workers included artifacts such as medication, latex gloves, telephone, watch and alcohol-based hand sanitizers. Documentation tools included the EHR and eMAR systems, desktop computers, copier, paper notes, handover sheets, and requisite skills of verbal communication, task prioritizing, time management, typing skills and knowledge about documentation.

In order to establish the relationship among the six activity theoretic components, a seventh component "process” was added in our model (Figure 2). "Process” referred to how subjects achieved their intended object, what steps and actions were taken at where and when, how tools were used, and how community rules and roles were instituted. The role of the tools and their mediating effect was manifested in this "process”. 


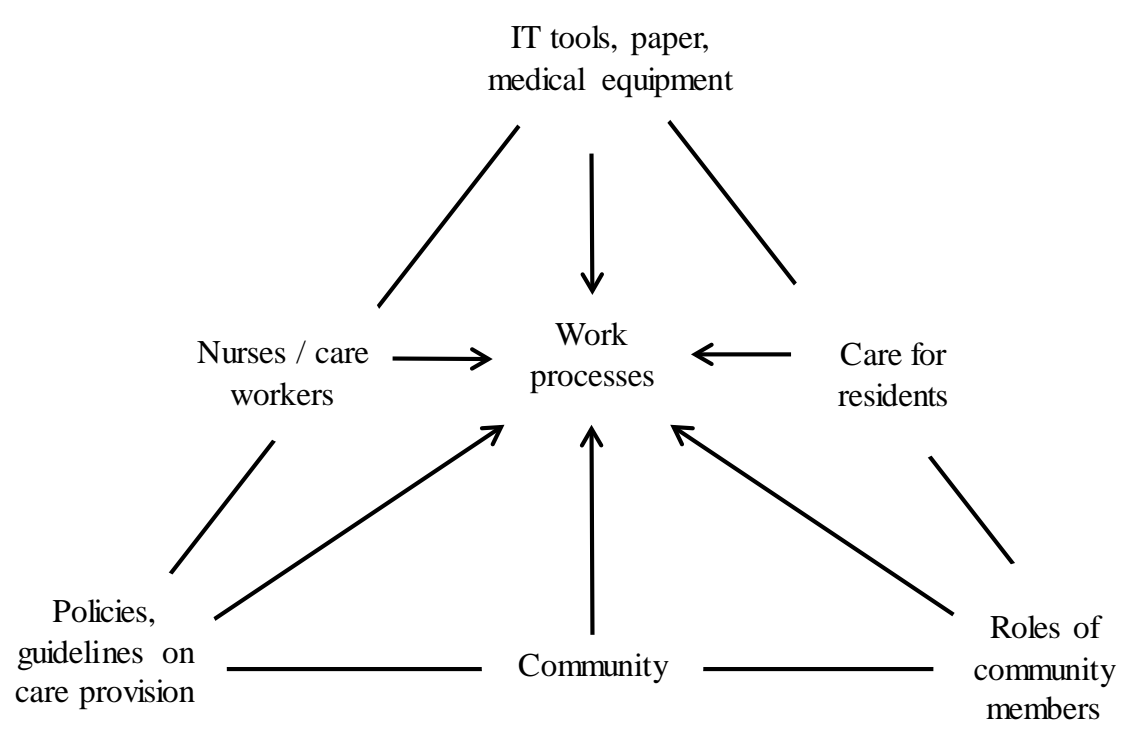

1

Figure 2. The work activity system of nurses and care workers.

The typical work process in morning shifts was as follows. During shift change between 6:30 am and 7:00 am, night shift staff would communicate resident care information to morning shift staff using a paper handover sheet. Morning shift staff would then started medication administration, which took about three hours, followed by a 20-minute break. They then conducted wound care, followed by another short break, before starting mid-day medication administration. Mid-day medication administration took about one hour because not every resident needed a medication. During this time, they also did point-of-care documentation.

After mid-day medication administration, they typically had a 30-minute lunch break, then conducted physical review of residents if needed. The rest of the shift was spent on a computer to enter wound care, incident report, and other necessary documentation on the EHR system. The shift completed with a handover task with the afternoon shift staff.

The two main work activities of this work activity system at the study sites were medication administration and wound care, which are described in detail next.

\subsubsection{Medication administration}

Process. The medication administration process included three key activities: preparation, administration and documentation. Preparation activity included adding relevant documents to the medication trolley, checking resident medications, and stocking medication for each resident from the fridge to trolley compartments labeled with resident names. In preparation of medication for a resident, the nurse or care worker checked the person's medication 
1 information, including medications name, dosage, whether these medications were to be

2 administered as pre-packed tablets or in unpacked form (e.g. liquid medication), and potential allergic reactions to each medication. The person then administered the medications to each resident and assisted with the medication if needed.

After administering the medication, the nurse or care worker signed on the person's records electronically (i.e., the eMAR system) at Unit 1 and on paper at other units.

Tools. The tools used in medication administration included medications, medication trolley, spoons and cups, pill crusher, a jar of water or juice, thickening fluid for mixing crushed pills, pathology waste rubbish bin, medication reference book, and knowledge about medication administration. Specific documentation tools for medication administration included the eMAR system and a Panasonic Toughbook portable device in Unit 1 and paper records in the other units.

Key documents. Medication administration records, whether electronic or paper, contained information about residents and their medications. For each resident, the records provided information about the resident's name, photo, allergy, gender, date of birth, doctor's name, number of medications, names of medications and time of administration. The records also provided space for nurses and care workers to sign on.

Paper notes and handover sheets were used in all units for specific medication administration activities that were not accommodated by the eMAR system. For example, blood glucose levels of diabetic residents were recorded on paper notes before insulin administration; this information was transcribed to the EHR system. Handover sheets were used to record and communicate critical medication-related information to staff on the next shift.

\subsubsection{Wound care}

Process. The wound care process started with preparing a wound care trolley by adding relevant would care charts, summary sheets and wound dressing tools. In a typical morning shift, there might be two to six residents requiring wound care. The number of wounds on each resident typically varied from one to five.

Wound care was typically conducted in residents' room. Upon completing this activity, the nurse or care worker documented the care on paper records at the point of care and entered into the EHR system after all wound care for the shift were completed.

Tools. The tools used for wound care included wound care dressings and other supplies (e.g. gauze, medical adhesive plaster), wound care trolley, knowledge about wound care, wound care book, and wound summary sheets. 
Key documents. The wound care book was the primary source of information during a wound care round. It included paper wound charts printed from the EHR system. These charts provided detailed information about each resident's wound progression and its management such as wound location, frequency of dressing change, and wound condition in the last care round. Nurses and care workers reviewed this information to determine the most appropriate way to deliver wound care and to prepare the right wound dressing for each resident.

They prepared a paper wound summary sheet in the form of a table to provide summarized information on residents' wound care needs for use during the wound care round. It included residents’ room/bed number, location of wound (e.g. back lower right leg), and scheduled dates and times for changing wound dressing or reviewing the wound. Each row in the sheet corresponded to one wound. Hence, a resident with multiple wounds might have several records in the summary sheet. The sheet was color-coded to indicate the shift (morning/afternoon) and time of wound care. This sheet was created and updated weekly by a participant nurse affectionately called the "wound girl" by her colleagues. Before starting a wound care round, the nurses and care workers transcribed wound information from the wound summary sheet to paper note, which was used for point-of-care documentation during and after wound care. Wounds on the paper note were crossed out after care was provided.

\subsection{Role of IT in the work of nurses and care workers}

Table 2 presents the different IT tools used by the participant nurses and care workers. The EHR system and computers were available at our study sites; however, only Unit 1 had the eMAR system installed on portable Panasonic Toughbook devices for point-of-care access. The primary role of IT was to help nurses and care workers conduct documentation activities, including collection, storage and retrieval of care information. In particular, IT was more advantageous than paper records in retrieving information to meet point-of-care information and communication needs.

Table 2. Information technologies used in nurses and care workers' work.

\begin{tabular}{|c|c|c|c|}
\hline $\begin{array}{l}\text { Information } \\
\text { technologies }\end{array}$ & Units & Functions & Work processes involved \\
\hline EHR & All units & $\begin{array}{l}\text { Providing forms for data entry, } \\
\text { storage and retrieval }\end{array}$ & $\begin{array}{l}\text { Medication administration } \\
\text { Wound care }\end{array}$ \\
\hline Desktop computers & All units & $\begin{array}{l}\text { - Access to the EHR system in the } \\
\text { offices }\end{array}$ & $\begin{array}{l}\text { Medication administration } \\
\text { Wound care }\end{array}$ \\
\hline Printer & All units & - $\quad$ Printing wound care charts & Wound care \\
\hline eMAR & Unit 1 & $\begin{array}{l}\text { Entry, storage and retrieval of } \\
\text { information about residents and } \\
\text { medications at the point of care }\end{array}$ & Medication administration \\
\hline
\end{tabular}




\begin{tabular}{|c|c|c|c|}
\hline & & $\begin{array}{l}\text { - } \begin{array}{l}\text { Management of medication } \\
\text { administration }\end{array} \\
\text { - } \quad \text { Automatically populating } \\
\text { "missed medication” into } \\
\text { progress notes } \\
\text { - Alerts of modifications done by } \\
\text { pharmacists to records }\end{array}$ & \\
\hline $\begin{array}{l}\text { Panasonic } \\
\text { Toughbook }\end{array}$ & Unit 1 & $\begin{array}{l}\text { - Access to the eMAR system at } \\
\text { the point of care }\end{array}$ & Medication administration \\
\hline
\end{tabular}

EHR: Electronic health record; eMAR: Electronic medication administration record

\section{$2 \quad$ 3.2.1 Real-time tracking of medication round progress}

3 Real-time tracking was important to ensure the timely management of the medication

4 administration process, especially when nurses and care workers could not medicate residents

5 in a sequential order. The tracking information could ensure that all residents receive their

6 medications.

In Unit 1, the eMAR system installed in the Panasonic Toughbook point-of-access device provided an easy, real-time and visible way to track the progress of the medication round. It provided information about residents and their medications. It also showed the medication "status" of each resident at any given point in time, whether the medication was taken, refused or yet to be taken by the resident. As the nurse or care worker administered medication to a resident and documented the information, the medication "status" was updated. The person could view the "status" of all residents in one screen and easily identified those who were yet to receive their medications.

In contrast, the nurses and care workers at the units that used paper records had to develop their own method to track medication administration. They pulled out the first page of the medication administration records of all residents in the beginning of a medication round and filed the page back after the person was medicated. Retrieving and refiling pages required additional time and effort, and increased the chances of missed medication if they forgot or missed a resident's medication page.

\subsubsection{Automation of the documentation process}

By organizational policy, information about "missed medication", irrespective of whether a resident missed the medication due to refusal, hospital visit, social leave, staff error, or other reasons, must be documented in both the person's medication administration records and in the EHR progress notes. In Unit 1, the eMAR system automatically populated this information to the EHR progress notes. However, in other units, this information was documented on paper records and on a paper note at the point of care. Information on the 
1 paper note was then manually entered into the EHR progress notes. Using the eMAR tool led

2 to improvement in accuracy and efficiency of documentation of medication administration.

\section{$3 \quad$ 3.2.3 Automation of the communication process}

4 In Unit 1, the eMAR system automatically alerted the nurses and care workers of any 5 modifications to the medication administration records done by pharmacists, physicians, etc.

6 However, in other units, this information was communicated verbally, often via phone calls.

7 The eMAR tool improved accuracy of information and reduced human error in the 8 communication process.

\section{$9 \quad$ 3.2.4 Information entry, storage and retrieval}

At the end of each wound care round, information recorded on paper notes were transcribed to the EHR system for future reference. If a new wound was found during that round, the EHR system created a new wound chart to record this wound. Charts for existing wounds under treatment were also updated in the EHR system. The paper wound care book was updated with printed copies of new charts and old charts were filed in a filing book. For resolved wounds, the corresponding charts in the EHR system were marked as complete and the paper wound charts were filed into the filing book. There was no difference among units on wound care.

\subsection{Contradictions}

The field observations identified two instances of primary contradiction (Figure 3 a), three instances of secondary contradiction (Figure $3 \mathrm{a}, \mathrm{b}$ ), one instance of tertiary contradiction (Figure 3 between a and b) and one instance of quaternary contradiction (Figure 3 between a and c). These contradictions were either introduced or resolved by IT. 

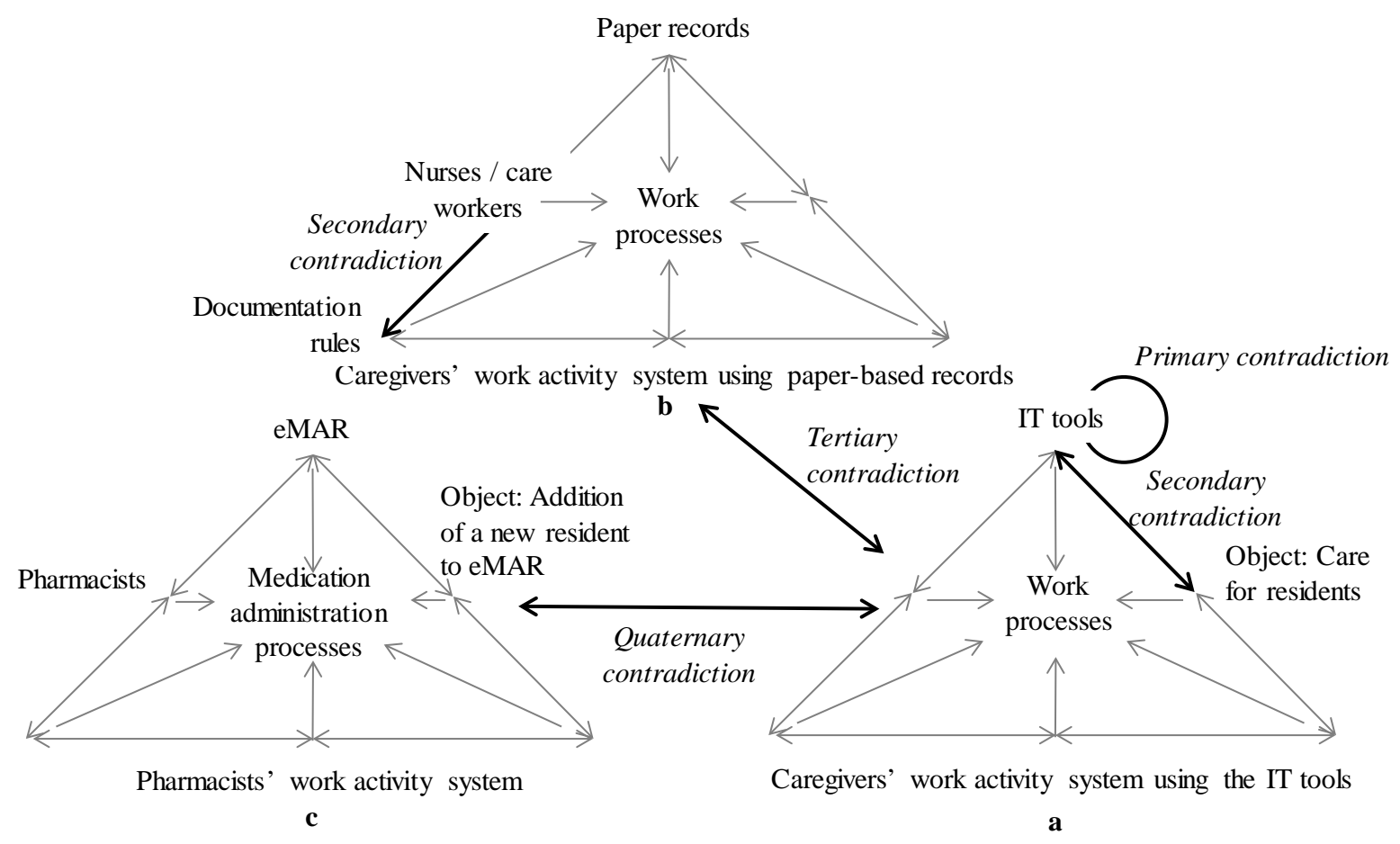

1

2 3

4

5

6

7

8

9

Figure 3. Information technology related contradictions identified in the work of nurses and care workers.

\subsubsection{Primary contradiction}

Primary contradictions are contradictions noted within one of the components of an activity system. Two primary contradictions were identified in the EHR system tool. This tool was intended to facilitate the continuity of care between staff working in different shifts. However, this goal was jeopardized when the system allowed duplication of wound charts for the same resident for the same wound. The EHR system did not remind a nurse or care worker of the existence of a specific wound chart in the system, and hence, if the person created a wound chart for a resident, the second person in a later shift might also create a second wound chart for the same wound without knowing that a corresponding wound chart already existed.

The other primary contradiction in the EHR system was the conflict between its inefficient information retrieval process and its goal of time-saving for documentation. For example, when searching for a wound chart, a nurse or care worker had to manually screen each electronic chart to locate the one that he or she was searching for. This was because the system did not allow searching by wound location - a critical information needed to identify the right wound chart. 


\subsubsection{Secondary contradiction}

Secondary contradictions are contradictions noted between two components of an activity system. Three secondary contradictions were identified. The first was observed between the eMAR tool and the object of caring for residents. If the nurses and care workers needed to check whether a resident was medicated in the last shift, the eMAR system did not provide this information, but instead showed only information related to the current medication time period. Although they could access this information by searching another system module, this additional search process created an additional burden and consumed the valuable work time. In units with no eMAR system, the nurses and care workers could easily find this information because it was documented on the same paper form.

The second secondary contradiction was between the portable point-of-access device tool and the object of caring for residents. When the device ran out of battery, the medication process was disturbed. Although the device prompted a low battery message, this message was often missed by the nurses and care workers who were busy on the floor with resident care. This situation forced them to rely on their memory to continue the medication round. Naturally, this contradiction negatively impacted service delivery and resident safety.

The third secondary contradiction was observed between the subject and the documentation rule. In units with paper records, several nurses and care workers documented before administering medication to residents or documenting for several residents at a time. This practice did not comply with the organizational rule which required documentation immediately following medication administration for each resident, before medicating the next person. This secondary contradiction between the subject and the documentation rule was facilitated by the flexibility of the paper records which could be easily flipped forward and backward. However, this was not observed with the eMAR system in Unit 1, where the system forced the nurses and care workers to document only after medicating a resident. This example illustrated that it was not always that new IT tools introduced contradictions; sometimes IT helped remove contradictions already in existence by enforcing the correct procedure.

\subsubsection{Tertiary contradiction}

Tertiary contradictions are contradictions noted between an activity system and a culturally different activity system. One tertiary contradiction was observed between the activity system using paper records and the activity system using a more advanced method- the EHR system. In wound care, the EHR system did not fit into the work process when nurses and care workers' needed to access and document care information. Therefore, they carried and used a 
stack of printed paper wound charts. At the end of the process, they transcribed all handwritten information on the charts into the EHR system. Such double data entry was not only inefficient, but introduced chances of error if the busy staff misplaced the paper records.

\subsubsection{Quaternary contradiction}

Quaternary contradictions are contradictions noted between the central activity system and its neighboring or interacting activity system. One quaternary contradiction was observed between the activity system of the nurses and care workers inside the LTCF and the activity system of pharmacists outside the LTCF. Although the eMAR system was used by both groups for new residents with no pre-existing medication profile in the system, the system required the pharmacy staff to manually create such a profile, which often took several days to create. During this time, the nurses and care workers could only use paper records to document medication administration information for these residents. A dual mode of medication documentation - older residents' information in the eMAR system and new residents' information on paper - could sometimes cause adverse consequences if a nurse or care worker forgot to check paper records and consequently forgot to medicate new residents. This contradiction indicated that the internal medication administration activity could be affected by the work activities of the external healthcare provider.

\section{Discussion}

This study explored how nurses and care workers work, the role of IT, and related contradictions in their work through the lens of activity theory. Activity theory was extended in this study by adding a new component "process" to the original theory. Understanding work processes is essential for understanding human activities, and more so for critical professions such as nursing. Nursing is a high-stress, high-stake work where failure (e.g. missing a medication dose) may have drastic and potentially life-ending consequences (Andersson et al., 2015, Liu et al., 2018). A recent study identified 15 process deviations in medication administration which may hinder resident safety in an Australian LTCF (Qian et al., 2018). This study also identified process deviations when the work processes were interrupted by technology failure (e.g. device ran out of battery), which forced the nurses and care workers to rely on memory to deliver medication, hindering resident safety. While this study examined only the work of nurses and care workers, it might have implications to other high-stress work, particularly in the healthcare sectors that deal with frail populations.

Nurses and care workers used a variety of IT tools to do their work, such as EHR, eMAR and point-of-access devices. The basic role of these tools was to facilitate the entry, storage and retrieval of critical information to help them provide better quality of care to their 
residents, improve their own work processes and maintain documentation for their peers and other parties. Information processing is a key component of most service activities and more so in the healthcare industry, where each resident is unique, has different care needs and requires customized care. The demand for mass delivery of such customized care to a frail population places enormous pressure on nurses and care workers and modern IT systems can help them by documenting and organizing their work (Fagerström et al., 2017). In our study, IT tools in Unit 1 assisted the nurses and care workers with managing medication administration to residents by providing easy, real-time, visible tracking of the medication round, expediting information retrieval and automating documentation and communication. A previous qualitative interview study conducted in nine Australian LTCFs also found that the IT tools improved the information retrieval, documentation and communication among the nurses and care workers (Zhang et al., 2012).

However, several contradictions were introduced or resolved by the use of IT in our study sites. It is important to identify and address these contradictions, which can otherwise lead to user resistance to IT. Furthermore, the presence of contradictions may cause users to devise "workarounds" to avoid using the system or use it in inappropriate ways, often leading to unintended consequences (Blijleven et al., 2017). Ignoring these contradictions makes it unlikely to realize the expected benefits of IT tools, such as work efficiency and effectiveness, lower costs and streamlined service delivery. Unfortunately, most organizational IT implementation processes end with system testing and user training, with little follow-up audits to evaluate the extent to which the system actually helps or contradicts users' work. In order to minimize potential contradictions, it is imperative that system designers understand the specific work activities the system is supposed to enable and view the work process from the users' perspective (Qian and Yu, 2014, Strauss et al., 2015).

In order to design a useful EHR system for nurses and care workers, system designers should experience a day in their life, observe what they do in their work, what information they need for their work and what rules and conventions they use in performing work. Just involving a few frontline nurses and care workers in the requirements analysis stage of system development to provide some isolated and disjointed feedback may not be adequate. In a recent study that investigated the effect of nursing participation in the design of a critical care information system at a Chinese hospital (Qin et al., 2017), two biomedical engineers used ethnographic method to understand the everyday work activities of the nurses, to gain insights into nurses' tacit knowledge, to capture and analyze their requirements and to translate the nursing needs to the language of the software developers for system 
1 development. During system implementation, one of the engineers watched system usage,

2 listened to nurses' feedback and followed up with appropriate adaptive maintenance to better customize the system to nurses' work. After the implementation, this person continued to be an onsite resource, providing training and support and improving system functionality. Comparison of outcome measurements before and after the implementation of the system found considerable improvement in the accuracy and efficiency of medication administration and nursing practices, while decreasing infection rate and mortality rate. These outcomes indicate the importance of thorough understanding of nurses' work and processes before, during and after system implementation to realize the intended benefits of IT use.

Our study identified several instances of misfits between the work processes of the nurses and care workers and the processes embedded in their work tools, similar to some of the prior studies in this area (Lin et al., 2013, Sadeghi et al., 2014). For example, despite the presence of the EHR system, the nurses and care workers printed wound care charts for each resident from the system for point-of-care documentation, hand wrote notes on those charts and later transcribed those notes back into the system. If the objective of the system is to automate resident care, then requiring paper forms for part of the task detracts from the intended goal of automation and may actually inject new contradictions. However, the dual process of documentation is necessary given the lack of point-of-care support for the EHR system. Providing a portable device for wound care rounds or introducing a point-of-care wound documentation system may help to address this contradiction by minimizing the repetition and streamlining the work (Florczak et al., 2012). Further, good documentation of wound care is indispensable for infection surveillance and prevention, comparison of wound healing progress between dressing changes, and continuity of care (Astagneau et al., 2009, Australian Wound Management Association, 2002, Ding et al., 2016).

This study also found that IT could resolve preexisting contradictions in organizational work processes. In units without the eMAR system, the nurses and care workers used paper records to document medication administration. Sometimes they did not document medication status of each resident immediately after completing that person's medication, but waited until later to document for several residents at a time. This type of "batch processing" was against organizational rules, but was nevertheless practiced because it saved time during medication rounds, albeit at the cost of resident safety and the organizational rules (Patterson et al., 2006, Vogelsmeier et al., 2008). The eMAR system eliminated this practice in Unit 1 by reinforcing the proper process defined in the documentation rule. 
As no paper records were available in the unit with eMAR system, the contradiction caused by the device battery failure forced the nurses and care workers to deliver medications from memory rather than a prescription. In this case, instead of facilitating their work process, the failure in IT tools could have an adverse impact on resident safety. Similar incidents including power outages, the lack of internet access and hardware breakdown had also been reported in prior research ( $\mathrm{Yu}$ et al., 2013). In our case, the portable device did show a message indicating low battery, but the message was located in one corner of the device screen, that it was often missed by the nurses and care workers. This contradiction can be addressed through upgrading the device with better alert function for battery status and standardizing a procedure for regular charging of these devices when not in use.

As the healthcare sector moves from technology implementation to "meaningful use", defined as the appropriate use of computer systems to improve data capture and sharing, clinical processes and health outcomes (HealthIT.gov, 2015), the barriers to meaningful use must be understood and strategies need to be designed to minimize the effect of these barriers (Heisey-Grove et al., 2014). Maintaining updated and accurate records was a critical first step in meaningful use and LTCFs and other healthcare facilities must critically examine the human-computer interface and the way it enables or hinders the work process (Qian et al., 2015, Zahabi et al., 2015), in order to realize meaningful use goals.

\subsection{Limitations}

Our study was not without limitations. Given the demands of the ethnographic study and resource and time limitations, not all nurses and care workers were observed. Only nine participants in Facility 1 and two participants in Facility 2, were observed. We did not observe any systematic differences in participants' work between the two facilities, leading us to infer that the limited sample size did not introduce any bias in our reported inferences. In other words, “theoretical saturation” with our sample of subjects was achieved.

The informal interviews and conversations were not audio-taped in the field, as it could interfere with the participants' ability to candidly provide information about their work. This limitation was addressed by triangulation of observational data and between observations, interviews, and documents.

There might be concern that collegial relationships developed between the observer and the participants may introduce bias. Actually, the collegial relationship helped promote a climate of trust that helped the researcher observe participants' behaviors and elicit candid responses from them. Potential personal bias was minimized by triangulating the participants' 
stated opinions with the observed behaviors, and by corroborating opinions from different participants to achieve "intersubjectivity".

\section{Conclusion}

This study investigated the work of nurses and care workers, the role of IT in their work and contradictions faced by them in two Australian LTCFs. Their work activity system was analyzed using the activity theory. Information technology played an important role to support information flow in this activity system, however it also caused contradictions. Seven contradictions were identified in their activity system at the primary, secondary, tertiary and quaternary level, all relating to the use of the IT tools such as the eMAR and EHR. A new component "process" was added to the activity theory.

\section{Acknowledgement}

The authors gratefully acknowledge all the participant nurses and care workers and the support from the management of the LTCFs.

\section{Conflicts of interest}

The authors have no conflicts of interest.

\section{Funding}

This research did not receive any funding.

\section{References}

Allen, D.K., Brown, A., Karanasios, S., Norman, A., 2013. How should technology-mediated organizational change be explained? A comparison of the contributions of critical realism and activity theory. MIS Quarterly 37 (3), 835-854.

Ampt, A., Westbrook, J., Creswick, N., Mallock, N., 2007. A comparison of self-reported and observational work sampling techniques for measuring time in nursing tasks. J Health Serv Res Policy 12 (1), 18-24.

Andersson, Å., Frank, C., Willman, A., Sandman, P.O., Hansebo, G., 2015. Adverse events in nursing: A retrospective study of reports of patient and relative experiences. International nursing review 62 (3), 377-385.

Astagneau, P., L'Hériteau, F., Daniel, F., Parneix, P., Venier, A.-G., Malavaud, S., Jarno, P., Lejeune, B., Savey, A., Metzger, M.-H., 2009. Reducing surgical site infection incidence through a network: Results from the French ISO-RAISIN surveillance system. Journal of Hospital Infection 72 (2), 127-134.

Australian Institute of Health and Welfare, 2018. Older Australia at a glance.

Australian Wound Management Association, 2002. Standards for wound management. Australian Wound Management Assoc.

Blijleven, V., Koelemeijer, K., Wetzels, M., Jaspers, M., 2017. Workarounds emerging from electronic health record system usage: Consequences for patient safety, effectiveness of care, and efficiency of care. JMIR human factors 4 (4). 
Cherry, B., Carter, M., Owen, D., Lockhart, C., 2008. Factors affecting electronic health record adoption in long-term care facilities. Journal for Healthcare Quality 30 (2), 3747.

Ding, S., Lin, F., Gillespie, B., 2016. Surgical wound assessment and documentation of nurses: An integrative review. Journal of Wound Care 25 (5), 232-240.

Engeström, Y., 2000. Activity theory as a framework for analyzing and redesigning work. Ergonomics 43 (7), 960-974.

Engeström, Y., 1987. Learning by expanding: An activity-theoretical approach to developmental research. Orienta-Konsultit Oy, Helsinki.

Engeström, Y., Sannino, A., 2011. Discursive manifestations of contradictions in organizational change efforts: A methodological framework. Journal of Organizational Change Management 24 (3), 368-387.

Fagerström, C., Tuvesson, H., Axelsson, L., Nilsson, L., 2017. The role of ICT in nursing practice: An integrative literature review of the Swedish context. Scandinavian Journal of Caring Sciences 31 (3), 434-448.

Fichman, R.G., Kohli, R., Krishnan, R., 2011. The role of information systems in healthcare: Current research and future trends. Information Systems Research 22 (3), 419-428.

Finkler, S.A., Knickman, J.R., Hendrickson, G., Lipkin, M.J., Thompson, W.G., 1993. A comparison of work-sampling and time-and-motion techniques for studies in health services research. Health Services Research 28 (5), 577-597.

Florczak, B., Scheurich, A., Croghan, J., Sheridan, J.P., Kurtz, D., McGill, W., McClain, B., 2012. An observational study to assess an electronic point-of-care wound documentation and reporting system regarding user satisfaction and potential for improved care. Ostomy/wound Management 58 (3), 46-51.

HealthIT.gov, 2015. Meaningful use definition \& objectives.

Heisey-Grove, D., Danehy, L.-N., Consolazio, M., Lynch, K., Mostashari, F., 2014. A national study of challenges to electronic health record adoption and meaningful use. Medical Care 52 (2), 144-148.

Hersh, W., 2009. A stimulus to define informatics and health information technology. BMC Medical Informatics and Decision Making 9 (1), 24.

Igira, F., Aanestad, M., 2009. Living with contradictions: Complementing activity theory with the notion of "installed base" to address the historical dimension of transformation. Mind, Culture, and Activity 16 (3), 209-233.

Karanasios, S., Allen, D., 2014. Mobile technology in mobile work: Contradictions and congruencies in activity systems. European Journal of Information Systems 23 (5), 529-542.

Kelley, T.F., Brandon, D.H., Docherty, S.L., 2011. Electronic nursing documentation as a strategy to improve quality of patient care. Journal of Nursing Scholarship 43 (2), 154-162.

Krefting, L., 1991. Rigor in qualitative research: The assessment of trustworthiness. American Journal of Occupational Therapy 45 (3), 214-222.

Kuutti, K., 1996. Activity theory as a potential framework for human-computer interaction research. Context and Consciousness: Activity Theory and Human-computer Interaction, 17-44.

Lin, F., Chaboyer, W., Wallis, M., Miller, A., 2013. Factors contributing to the process of intensive care patient discharge: An ethnographic study informed by activity theory. International Journal of Nursing Studies 50 (8), 1054-1066.

Liu, X., Zheng, J., Liu, K., Baggs, J.G., Liu, J., Wu, Y., You, L., 2018. Hospital nursing organizational factors, nursing care left undone, and nurse burnout as predictors of 
patient safety: A structural equation modeling analysis. International Journal of Nursing Studies.

McEwan, B., 2008. Defining the scope of practice of enrolled nurses in medication administration in Australia: A review of the legislation. Collegian 15 (3), 93-101.

Munyisia, E.N., Yu, P., Hailey, D., 2011. The changes in caregivers' perceptions about the quality of information and benefits of nursing documentation associated with the introduction of an electronic documentation system in a nursing home. International Journal of Medical Informatics 80 (2), 116-126.

Munyisia, E.N., Yu, P., Hailey, D., 2011. How nursing staff spend their time on activities in a nursing home: An observational study. Journal of Advanced Nursing 67 (9), 19081917.

Nardi, B.A., 1995. Context and consciousness: Activity theory and human-computer interaction. Mit Press.

National Enrolled Nurse Association of Australia, Becoming an enrolled nurse.

Ngoma, C., Igira, F., 2012. Contradictions in collecting and recording maternal health data at the community level: A case study from two districts in Tanzania. Journal of Health Informatics in Developing Countries 6 (2), 509-520.

Office for National Statistics, 2014. National population projections, 2012-based reference volume. Office for National Statistics,.

Ortman, J.M., Velkoff, V.A., Hogan, H., 2014. An aging nation: The older population in the United States. Washington, DC, US, pp. 25-1140.

ØSterlund, C., 2007. Genre combinations: A window into dynamic communication practices. Journal of Management Information Systems 23 (4), 81-108.

Patterson, E., Rogers, M., Chapman, R., Render, M., 2006. Compliance with intended use of bar code medication administration in acute and long-term care: An observational study. Human Factors 48 (1), 15 - 22.

Qian, S., Yu, P., 2014. Fitting clinical workflow: The case for wound care in a residential aged care home. In: Grain, H., Martin-Sanchez, F., Schaper, L.K. (Eds.), Investing in e-health: People, knowledge and technology for a healthy future. IOS press, Netherlands, pp. 130-136.

Qian, S., Yu, P., Hailey, D., 2016. Nursing staff work patterns in a residential aged care home: A time-motion study. Australian Health Review 40 (5), 544-554.

Qian, S., Yu, P., Hailey, D., Wang, N., Bhattacherjee, A., 2018. Medication administration process in a residential aged care home: An observational study. Journal of Nursing Management 26 (8).

Qian, S., Yu, P., Hailey, D.M., 2015. The impact of electronic medication administration records in a residential aged care home. International Journal of Medical Informatics 84 (11), 966-973.

Qian, S., Yu, P., Zhang, Z., Hailey, D., Davy, P., Nelson, M., 2012. The work pattern of personal care workers in two Australian nursing homes: A time-motion study. BMC Health Services Research 12 (1), 305.

Qin, Y., Zhou, R., Wu, Q., Huang, X., Chen, X., Wang, W., Wang, X., Xu, H., Zheng, J., Qian, S., Bai, C., Yu, P., 2017. The effect of nursing participation in the design of a critical care information system: A case study in a chinese hospital. BMC Medical Informatics and Decision Making 17 (1), 165.

Reeves, S., Kuper, A., Hodges, B.D., 2008. Qualitative research methodologies: Ethnography. BMJ 337.

Sadeghi, P., Andreev, P., Benyoucef, M., Momtahan, K., Kuziemsky, C., 2014. Activity theory driven system analysis of complex healthcare processes. pp. 1-14. 
Senate Community Affairs Committee, 2017. Future of Australia's aged care sector workforce. Australian Government Canberra.

Strauss, A.T., Martinez, D.A., Garcia-Arce, A., Taylor, S., Mateja, C., Fabri, P.J., ZayasCastro, J.L., 2015. A user needs assessment to inform health information exchange design and implementation healthcare information systems. BMC Medical Informatics and Decision Making 15 (1).

Taxis, K., Barber, N., 2003. Causes of intravenous medication errors: An ethnographic study. BMJ Quality \& Safety 12 (5), 343-347.

Vogelsmeier, A.A., Halbesleben, J.R., Scott-Cawiezell, J.R., 2008. Technology implementation and workarounds in the nursing home. Journal of the American medical informatics association 15 (1), 114-119.

Wartofsky, M.W., 2012. Models: Representation and the scientific understanding. Springer Science \& Business Media.

Willis, E., Price, K., Bonner, R., Henderson, J., Gibson, T., Hurley, J., Blackman, I., Toffoli, L., Currie, T., 2016. Meeting residents' care needs: A study of the requirement for nursing and personal care staff.

Woll, A., Bratteteig, T., 2018. Activity theory as a framework to analyze technologymediated elderly care. Mind, Culture, and Activity 25 (1), 6-21.

Yu, P., Zhang, Y., Gong, Y., Zhang, J., 2013. Unintended adverse consequences of introducing electronic health records in residential aged care homes. International Journal of Medical Informatics 82 (9), 772-788.

Zahabi, M., Kaber, D.B., Swangnetr, M., 2015. Usability and safety in electronic medical records interface design: A review of recent literature and guideline formulation. Human Factors 57 (5), 805-834.

Zhang, Y., Yu, P., Shen, J., 2012. The benefits of introducing electronic health records in residential aged care facilities: A multiple case study. International Journal of Medical Informatics 81 (10), 690-704. 